\title{
The effect of moving to East Village, the former London 2012 Olympic and Paralympic Games Athletes' Village, on mode of travel (ENABLE London study, a natural experiment)
}

Elizabeth S. Limb ${ }^{1 *+}$, Duncan S. Procter ${ }^{2,3+}$, Ashley R. Cooper ${ }^{2,3}$, Angie S. Page ${ }^{2,3}$, Claire M. Nightingale ${ }^{1}$, Bina Ram', Aparna Shankar ${ }^{1}$, Christelle Clary ${ }^{4}$, Daniel Lewis ${ }^{4}$, Steven Cummins ${ }^{4}$, Anne Ellaway ${ }^{5}$, Billie Giles-Corti ${ }^{6}$,

Peter H. Whincup', Alicja R. Rudnicka', Derek G. Cook ${ }^{1}$ and Christopher G. Owen ${ }^{1}$

\begin{abstract}
Background: Interventions to encourage active modes of travel (walking, cycling) may improve physical activity levels, but longitudinal evidence is limited and major change in the built environment / travel infrastructure may be needed. East Village (the former London 2012 Olympic Games Athletes Village) has been repurposed on active design principles with improved walkability, open space and public transport and restrictions on residential car parking. We examined the effect of moving to East Village on adult travel patterns.

Methods: One thousand two hundred seventy-eight adults (16+ years) seeking to move into social, intermediate, and market-rent East Village accommodation were recruited in 2013-2015, and followed up after 2 years. Individual objective measures of physical activity using accelerometry (ActiGraph GT3X+) and geographic location using GPS travel recorders (QStarz) were time-matched and a validated algorithm assigned four travel modes (walking, cycling, motorised vehicle, train). We examined change in time spent in different travel modes, using multilevel linear regresssion models adjusting for sex, age group, ethnicity, housing group (fixed effects) and household (random effect), comparing those who had moved to East Village at follow-up with those who did not.

Results: Of 877 adults (69\%) followed-up, 578 (66\%) provided valid accelerometry and GPS data for at least 1 day ( $\geq 540 \mathrm{~min}$ ) at both time points; half had moved to East Village. Despite no overall effects on physical activity levels, sizeable improvements in walkability and access to public transport in East Village resulted in decreased daily vehicle travel $(8.3$ mins, $95 \% \mathrm{Cl} 2.5,14.0)$, particularly in the intermediate housing group $(9.6$ mins, $95 \% \mathrm{Cl} 2.2,16.9)$, and increased underground travel $(3.9$ mins, $95 \% \mathrm{Cl} 1.2,6.5)$, more so in the market-rent group $(11.5 \mathrm{mins}, 95 \% \mathrm{Cl} 4.4$, 18.6). However, there were no effects on time spent walking or cycling.
\end{abstract}

Conclusion: Designing walkable neighbourhoods near high quality public transport and restrictions on car usage, may offer a community-wide strategy shift to sustainable transport modes by increasing public transport use, and reducing motor vehicle travel.

Keywords: Built environment, Travel mode, Physical activity, Walking, Cycling, Housing tenure

\footnotetext{
* Correspondence: elimb@sgul.ac.uk

ES Limb and DS Procter are Joint first author contribution

${ }^{\dagger}$ E. S. Limb and D. S. Procter contributed equally to this work.

'Population Health Research Institute, St George's, University of London,

London, UK

Full list of author information is available at the end of the article
}

(c) The Author(s). 2020 Open Access This article is distributed under the terms of the Creative Commons Attribution 4.0 International License (http://creativecommons.org/licenses/by/4.0/), which permits unrestricted use, distribution, and reproduction in any medium, provided you give appropriate credit to the original author(s) and the source, provide a link to the Creative Commons license, and indicate if changes were made. The Creative Commons Public Domain Dedication waiver (http://creativecommons.org/publicdomain/zero/1.0/) applies to the data made available in this article, unless otherwise stated. 


\section{Background}

A low level of physical activity poses a serious threat to health due to its association with premature mortality and non-communicable disease [1]. The healthcare cost of low physical activity is high, costing the UK National Health Service (NHS) £0.9 billion in 2006/07 alone [2]. This has led to physical activity recommendations becoming enshrined into health policy, with guidelines generally recommending at least $150 \mathrm{~min}$ of moderateintensity or $75 \mathrm{~min}$ of vigorous-intensity activity per week, accompanied by muscle strengthening exercises $[1,3,4]$. In the UK, only a third of men and $40 \%$ of women report these recommended levels of activity [5]. However, since recent evidence suggests that even low levels of physical activity can be beneficial for health, particularly being protective against cardiovascular disease, there is a shift towards encouraging everyone, particularly those with low levels of physical activity, to become a little more active $[6,7]$.

While there is inconclusive evidence that community-wide interventions to increase physical activity are effective [8], walking is a universal form of physical activity available to most people, and strategies to promote walking could yield important health benefits including reducing the risk of obesity [9] and contributing to tackling climate change [10]. Changing the built environment to promote use of public transport may offer a strategy to increase physical activity levels, through increased walking and cycling [11-13], which could potentially impact on health [14-16]. However, the evidence-base is largely cross-sectional, and longitudinal studies are needed to demonstrate cause and effect [17]. Moreover, accuracy in quantifying the active component of everyday travel has been hampered by use of selfreported travel diaries, which can often be imprecise and unreliable $[18,19]$. Objective measures are being used increasingly to identify travel modes. By combining data from accelerometers and global positioning system (GPS) monitors, machine learning tools are able to automatically discriminate between different travel modes [20, 21]. For example, we have recently validated such an approach, making use of a gradient boosting machine learning tool [22]. There have been calls for high quality evidence to evaluate the effect of environmental interventions on health behaviours, particularly physical activity, making use of natural experiments where the population effects of change in travel infrastructure can be examined [23-25]. However, sizeable alterations in travel infrastructure and studies with sufficient numbers are needed to demonstrate change in active travel behaviour, and given the practical difficulties and high costs involved in making marked changes to the built environment, few opportunities arise [26]. In addition, the degree of change should ideally be compared with a control population who are similar socio-demographically but not exposed to the same change in travel infrastructure [27], and analysis conducted within a rapid time scale to distinguish any potential effects (favourable or otherwise) from underlying trends in physical activity levels over time.

The East Village neighbourhood, the former London 2012 Olympics Athletes' Village offered an opportunity for just such a natural experiment [28]. East Village is a purpose-built mixed-use residential development, and was built on active design principles specifically to encourage active living, by improving neighbourhood walkability and access to public transport and open space with restrictions on vehicle parking [28] Utilising Geographic Information Systems (GIS) allows objective and detailed characterisation of built environment features at baseline and follow-up, including the ability to quantify changes in walkability, access to green and public open space, and access to public transport facilities. Adults seeking to move into differently tenured accommodation in East Village (social, intermediate / affordable, and market-rent), were recruited and followed-up after 2 years, once half had relocated to East Village [28]. The present study examines changes in travel mode (walking, cycling, motorised vehicle and train use) using objective measures in those who moved to East Village compared with those who did not.

\section{Methods}

Between January 2013 and December 2015, the Examining Neighbourhood Activities in Built Living Environments in London (ENABLE London) study recruited adults seeking to move into three different housing tenures in East Village: social housing, recruited by East Thames Group Housing Association; intermediate housing (affordable market-rent / shared ownership / shared equity), recruited by Triathlon Homes; and market-rent, recruited by Get Living London [28]. For social housing, eligible participants were those currently living in or on a waiting list for social housing in the London Borough of Newham. Priority was based on a points system which included current living conditions, earnings and health circumstances. Unfortunately, the points scoring system could not be shared with the investigators. Eligibility for intermediate accommodation was based on a rigorous financial process - they were required to be first-time buyers, living or working in London and with an annual household income less than $£ 66,000$ for 1 - or 2-bedroom homes or less than $£ 80,000$ 
for 3-bedroom homes. There were no financial restrictions for those seeking market-rent accommodation. Those applying to move into East Village social housing were provided with information about the study and invited to take part by East Thames Group representatives directly, while the ENABLE team (in association with Triathlon Homes and Get Living London) invited those from intermediate and market-rent groups. Those who agreed to take part and subsequently chose to move to East Village were exposed to the intervention. Those who took part but did not move to East Village, choosing to stay in their current housing or move elsewhere, represented the Control group. Follow-up of the cohort was carried out after 2 years from January 2015 to December 2017 after half had moved to East Village. Assessments at both time points were similar and carried out during home visits by a team of trained fieldworkers (with 1 or more participants per household); details of the assessments have been described elsewhere [28]. In brief, these included individual questionnaires and objective measures of physical activity levels with concurrent recording of geographic location over a 7-day period. Details of these measures are provided below.

\section{Physical activity and geographic location}

At baseline and follow-up, participants were asked to wear an ActiGraph GT3X+ accelerometer (ActiGraph LLC, Florida, USA) and a GPS receiver (Qstarz BT1000XT; Taipei, Taiwan), set to record location every $10 \mathrm{~s}$, on an elasticated belt around the waist during waking hours for 7 consecutive days. Accelerometers provided objective measures of daily physical activity, which have been previously validated against gold standard assessment of energy expenditure [29], and more recently, against oxygen consumption [30]. Combined ActiGraph accelerometer and GPS travel recorder data were analysed using a previously described automated machine learning algorithm, which allocated each 10-s epoch of combined data to one of four travel modes, quantifying the daily time spent (i) walking, (ii) cycling, (iii) traveling by motorised vehicle (including car/van/bus/motorbike) or (iv) overground train. A fifth category classified recorded time where a journey was not taking place and the participant was stationary, e.g., sitting indoors at home or at work or stationary outside [22]. Gaps in the data due to loss of GPS signal were further classified as "underground" if the GPS signal was lost or regained within close proximity $(200 \mathrm{~m})$ of an underground station, and the time lapse between loss and regained signal was from $2 \mathrm{~min}$ to $2 \mathrm{~h}$. However, as underground trains in the London transport system also run above ground, so there was potential for misclassification between "underground" and "overground train" modes of travel. The 10-s epoch data were then summed to provide daily minutes in each travel mode and total daily GPS minutes. Walking and cycling minutes were also combined to provide a measure of "active travel". To minimise bias due to low wear time of the GPS monitor or low GPS recording activity, days were only included in the analysis if there was a corresponding day of $\geq 540 \mathrm{~min}$ of valid accelerometry data, in line with the criteria specified a priori for the main accelerometry outcomes.

\section{Environmental exposures}

Participants were geocoded to the centroid of the footprint of their building of residence at both baseline and follow-up. At both time points, participants were assigned the value of the closest available Public Transport Accessibility Level (PTAL) score [31] from their home address, as a measure of accessibility to public transport. Measures of neighbourhood walkability provided a relative index, derived by combining scores from three different domains; (i) land-use mix (as a measure of residential, commercial, office, entertainment and institutional building footprints), (ii) street connectivity (from the number of 3 or more branch road junctions), and (iii) residential density, within a within a $1 \mathrm{~km}$ street network home address-centred buffer using Ordnance Survey (OS) data [32]. A park proximity variable was computed as the shortest street network distance from the residential addresses to the nearest entrance of the closest park. Using data from Greenspace Information for Greater London (GiGL) [33], three types of park were considered (Metropolitan, District and Local), based on their size and the number and type of facilities available, as described in the Greater London Authority (GLA) reference plan [34].

\section{Covariates}

Laptop-based self-completion questionnaires were used to collect data on age, sex, self-defined ethnicity, work status, occupation and car/van ownership. Participants were categorised as 'White', 'Asian', 'Black', 'Mixed', or 'Other'; the latter two categories were combined in the analysis. Occupation based socioeconomic status was coded using the National Statistics Social-Economic Classification (NS-SEC) to code participants into 'higher managerial or professional occupations', 'intermediate occupations', and 'routine or manual occupations'. [35] An additional 'economically inactive' category included those seeking employment, unable to work due to disability or illness, retired, looking after home and family, and students [36]. Two neighbourhood perception scores, measuring crime (i.e., vandalism, feeling unsafe to walk in neighbourhood, presence of threatening groups) and neighbourhood quality (i.e., accessible features, attractiveness, and enjoyment of living in neighbourhood), were derived at baseline using exploratory 
factor analysis on 14 neighbourhood perception items in the questionnaire $[37,38]$, and the same items were used to obtain scores at follow-up.

\section{Statistical analysis}

For each motion category (travel mode, underground and stationary), average daily minutes at baseline were derived using multi-level linear regression models (level 1 was day within individual and level 2 was individual). Daily was regressed on day-order-of-wear, day-of-week and month-of-wear as fixed effects and participant as a random effect to allow for up to 7 days recording for each individual. The mean of the within-person residuals for each participant was obtained and added to the population mean to produce an unbiased average daily estimate for each participant. This was repeated for the follow-up data. The change in average daily minutes from baseline to follow-up for each travel mode was then examined using multilevel linear regression models, where level 1 was individual and level 2 was household. For each travel mode, average daily minutes at follow-up was regressed on average daily minutes at baseline adjusting for East Village/Control group, sex, age group, ethnic group and housing group as fixed effects, and household as a random effect. The regression coefficient for East Village/Control group thus provided an estimate of the average within-person change in the East Village group compared with the average within-person change in the Control group, minimising bias and maintaining power. Stratified models by housing group examined the effects in the different housing groups. Checks were carried out to confirm that the distribution of residuals from the models were normally distributed. Sensitivity analyses were carried out for the GPS outcomes: (i) restricting analyses to those who were working or studying at baseline; (ii) repeating analyses for weekdays only and weekend days only; (iii) multiple imputation methods to assess the impact of missing data from those who provided GPS data at baseline but not at follow-up. STATA mi impute commands were used with linear regression models and 40 imputations to impute GPS outcome data, conditional on the model variables (baseline GPS outcome, East Village / Control group, sex, age group, ethnic group and housing group).

\section{Results}

At baseline, 1063/1278 adults (83\%) provided GPS data of whom 991 also provided at least one corresponding day of $\geq 540 \mathrm{~min}$ accelerometer wear time. At follow-up, 877 adults were re-examined, half had moved to East Village; 714 (81\%) provided GPS data, 681 with at least one corresponding day with $\geq 540 \mathrm{~min}$ accelerometry wear time. Longitudinal analyses were restricted to 578 who had valid GPS data at both baseline and follow-up and baseline characteristics for these 578 adults are shown in Table 1 by East Village/Control group and housing group. Age and sex patterns were similar to those for both the 877 who were followed-up and the 1278 recruited at baseline [39]. However, those with complete GPS data were more likely to be of white ethnic origin and higher managerial, professional or intermediate occupations. In the social housing group, the East Village and Control group were similar in age, sex and socio-economic distributions, but the East Village group were more likely to be of black ethnic origin. In the intermediate group, the East Village group were more likely to be younger, male, of white ethnic origin and economically active. In the market-rent group, age, sex, ethnic group and socio-economic status were similar in the East Village and Control groups. There was no difference between the East Village group and Control group in the proportion of households who owned a car at baseline. Slightly fewer of the East Village group were working at baseline and 24\% were classified as economically inactive compared with $18 \%$ of the Control group. Using public transport to travel to work or study was reported more frequently amongst those who subsequently moved into East Village ( $p=0.004$ for all housing groups combined). Use of private transport and walking/cycling for travel to work or study were similar in the East Village and Control groups, although social housing participants were more likely to use private transport and less likely to walk/cycle compared with intermediate and market-rent participants. Time spent in the different GPS motion categories were similar in the East Village and Control groups, although the Control group recorded slightly higher mean walking and cycling minutes at baseline. The intermediate and market-rent housing groups recorded more walking, cycling, overground and underground train minutes and fewer vehicle minutes compared with the social housing group.

Table 2 shows the change in neighbourhood perception and built environment variables for the East Village and Control groups. Compared with baseline data, those participants who had moved to East Village showed significant improvements in their built environments, living closer to their nearest park (on average living $547 \mathrm{~m}$ closer), improved access to public transport and living in a more walkable area (with appreciable increases in walkability). They also reported more positive perceptions of their local area, with improved perceived neighbourhood crime and quality scores. These differences were most marked for social housing participants.

The effect of moving to East Village on time spent in different travel modes is shown in Table 3, and summary data in Additional file 1: Table S1. Overall, there was little change in participants' walking or cycling minutes. However, vehicle minutes decreased on average by 8.3 
Table 1 Baseline characteristics and GPS outcomes for those with GPS data at baseline and follow-up

\begin{tabular}{|c|c|c|c|c|c|c|c|c|c|}
\hline \multirow[t]{3}{*}{$\bar{N}$} & \multicolumn{2}{|c|}{ All housing groups } & \multirow[t]{3}{*}{$p$-value } & \multicolumn{2}{|c|}{ Social housing group } & \multicolumn{2}{|c|}{$\begin{array}{l}\text { Intermediate housing } \\
\text { group }\end{array}$} & \multicolumn{2}{|c|}{$\begin{array}{l}\text { Market rent housing } \\
\text { group }\end{array}$} \\
\hline & $\begin{array}{l}\text { Control } \\
285\end{array}$ & $\begin{array}{l}\text { East Village } \\
293\end{array}$ & & $\begin{array}{l}\text { Control } \\
74\end{array}$ & $\begin{array}{l}\text { East Village } \\
127\end{array}$ & $\begin{array}{l}\text { Control } \\
141\end{array}$ & $\begin{array}{l}\text { East Village } \\
142\end{array}$ & $\begin{array}{l}\text { Control } \\
70\end{array}$ & $\begin{array}{l}\text { East Village } \\
24\end{array}$ \\
\hline & n (\%) & n (\%) & & n (\%) & n (\%) & n (\%) & n (\%) & n (\%) & n (\%) \\
\hline$\overline{\text { Age }}$ & & & 0.005 & & & & & & \\
\hline $16-24$ & $44(15 \%)$ & $68(23 \%)$ & & $7(9 \%)$ & $26(20 \%)$ & $20(14 \%)$ & $29(20 \%)$ & $17(24 \%)$ & $13(54 \%)$ \\
\hline $25-34$ & $116(41 \%)$ & $133(45 \%)$ & & $18(24 \%)$ & $34(27 \%)$ & 65 (46\%) & $93(65 \%)$ & $33(47 \%)$ & $6(25 \%)$ \\
\hline $35-49$ & $100(35 \%)$ & $80(27 \%)$ & & 44 (59\%) & $57(45 \%)$ & $46(33 \%)$ & $19(13 \%)$ & $10(14 \%)$ & $4(17 \%)$ \\
\hline $50+$ & $25(9 \%)$ & $12(4 \%)$ & & $5(7 \%)$ & $10(8 \%)$ & $10(7 \%)$ & $1(1 \%)$ & $10(14 \%)$ & $1(4 \%)$ \\
\hline Sex: female & $173(61 \%)$ & 159 (54\%) & 0.12 & $58(78 \%)$ & $91(72 \%)$ & $82(58 \%)$ & $57(40 \%)$ & $33(47 \%)$ & $11(46 \%)$ \\
\hline Ethnic group & & & 0.001 & & & & & & \\
\hline White & $152(53 \%)$ & 161 (55\%) & & $17(23 \%)$ & $24(19 \%)$ & $87(62 \%)$ & 117 (82\%) & $48(69 \%)$ & $20(83 \%)$ \\
\hline Black & $48(17 \%)$ & $78(27 \%)$ & & $22(30 \%)$ & 75 (59\%) & $21(15 \%)$ & $3(2 \%)$ & $5(7 \%)$ & $0(0 \%)$ \\
\hline Asian & $57(20 \%)$ & $30(10 \%)$ & & $29(39 \%)$ & $13(10 \%)$ & $23(16 \%)$ & $15(11 \%)$ & $5(7 \%)$ & $2(8 \%)$ \\
\hline Other & $28(10 \%)$ & $24(8 \%)$ & & $6(8 \%)$ & 15 (12\%) & $10(7 \%)$ & $7(5 \%)$ & $12(17 \%)$ & $2(8 \%)$ \\
\hline NS-SEC ${ }^{a}$ & & & 0.03 & & & & & & \\
\hline Higher managerial/professional & $163(57 \%)$ & $130(45 \%)$ & & $17(23 \%)$ & $16(13 \%)$ & $97(69 \%)$ & 99 (70\%) & $163(70 \%)$ & $15(63 \%)$ \\
\hline Intermediate occupations & $43(15 \%)$ & $56(19 \%)$ & & $12(16 \%)$ & $21(17 \%)$ & $18(13 \%)$ & $29(21 \%)$ & $13(19 \%)$ & $6(25 \%)$ \\
\hline Routine/manual occupations & $29(10 \%)$ & $33(11 \%)$ & & $16(22 \%)$ & $24(19 \%)$ & $11(8 \%)$ & $9(6 \%)$ & $2(3 \%)$ & $0(0 \%)$ \\
\hline Economically inactive & $50(18 \%)$ & $71(24 \%)$ & & $29(39 \%)$ & $64(51 \%)$ & $15(11 \%)$ & $4(3 \%)$ & $6(9 \%)$ & $3(13 \%)$ \\
\hline Car or van in household & $111(46 \%)$ & $104(46 \%)$ & 0.96 & $31(53 \%)$ & $47(51 \%)$ & $55(46 \%)$ & $49(43 \%)$ & $25(41 \%)$ & $8(40 \%)$ \\
\hline Currently working or studying & $245(86 \%)$ & $240(82 \%)$ & 0.18 & $51(69 \%)$ & $80(63 \%)$ & $128(91 \%)$ & $138(97 \%)$ & $66(94 \%)$ & $22(92 \%)$ \\
\hline \multicolumn{10}{|c|}{ Mode of travel to or from work / study (not mutually exclusive) } \\
\hline Public transport & $156(67 \%)$ & $182(79 \%)$ & 0.004 & $31(66 \%)$ & $56(74 \%)$ & $83(67 \%)$ & $110(82 \%)$ & $42(67 \%)$ & $16(76 \%)$ \\
\hline Private car/motorbike/taxi & $35(15 \%)$ & $28(12 \%)$ & 0.36 & $10(21 \%)$ & $16(21 \%)$ & $19(15 \%)$ & $10(7 \%)$ & $6(10 \%)$ & $2(10 \%)$ \\
\hline Walk/cycle & $141(61 \%)$ & $128(55 \%)$ & 0.27 & $19(40 \%)$ & $40(53 \%)$ & $82(67 \%)$ & $77(57 \%)$ & $40(63 \%)$ & $11(52 \%)$ \\
\hline GPS motion category (minutes) & mean (sd) & mean (sd) & $p$-value & mean (sd) & mean (sd) & mean (sd) & mean $(s d)$ & mean (sd) & mean $(s d)$ \\
\hline Walking & $39.7(25.9)$ & $37.7(24.5)$ & 0.35 & $30.6(21.4)$ & $31.3(25.0)$ & $40.9(24.3)$ & $43.3(22.2)$ & $46.7(30.5)$ & $38.2(27.6)$ \\
\hline Cycling & $6.1(13.2)$ & $3.5(6.7)$ & 0.003 & $2.3(2.7)$ & $2.5(4.1)$ & $7.0(13.6)$ & $4.7(8.6)$ & $8.2(17.5)$ & $2.1(3.6)$ \\
\hline Walking + cycling & $45.8(30.0)$ & $41.3(26.4)$ & 0.06 & $32.9(22.0)$ & $33.8(25.8)$ & $48.0(28.4)$ & $48.1(24.9)$ & $54.9(35.8)$ & $40.2(28.1)$ \\
\hline Motorised vehicle & $37.3(37.7)$ & $38.0(38.9)$ & 0.84 & $42.6(47.0)$ & $48.8(47.5)$ & $36.5(31.5)$ & $29.4(27.9)$ & $33.5(38.0)$ & $31.6(30.5)$ \\
\hline Overground train & $14.6(21.3)$ & $14.5(18.9)$ & 0.98 & $8.3(12.2)$ & $8.5(13.7)$ & $16.5(22.6)$ & $20.4(22.0)$ & $17.4(24.8)$ & $11.6(11.7)$ \\
\hline Underground train ${ }^{b}$ & $14.3(17.5)$ & $15.1(17.5)$ & 0.55 & $11.6(20.2)$ & $8.0(14.8)$ & $14.9(16.7)$ & $20.9(18.0)$ & $15.8(15.6)$ & $18.9(15.0)$ \\
\hline Stationary, incl inside \& outside & $440(193)$ & 449 (188) & 0.58 & 507 (192) & $496(184)$ & $421(190)$ & 418 (179) & $407(184)$ & $380(207)$ \\
\hline Total GPS time & $552(207)$ & $558(195)$ & 0.73 & $602(201)$ & $596(190)$ & $537(206)$ & 537 (188) & $529(210)$ & $482(225)$ \\
\hline
\end{tabular}

${ }^{a}$ Economically inactive includes those not part of the labour force who are unemployed or not available for work, including students and house carers bUnderground minutes are assumed from portions of missing GPS signal where the GPS signal is lost within $200 \mathrm{~m}$ of an underground station and regained within $200 \mathrm{~m}$ of a different underground station

min per day, with greater effects in the intermediate housing group ( 9.6 min decrease, $95 \% \mathrm{CI}-16.9$ to -2.2 , $p=0.01$ ), and time spent traveling by underground increased by $3.9 \mathrm{~min}$, particularly in the market-rent housing group (11.5 min, 95\% CI 4.4 to $18.6, p=0.001$ ). There were large decreases in the East Village group in both stationary and total minutes of recorded time. These varied by housing group, the largest decreases recorded by the social housing group and the smallest decrease by the market-rent housing group. Manual inspection of the data suggested that this was due to reductions in indoor recording among the East Village group, with the GPS signal being blocked by East Village housing. Restricting the analysis to those who were working or studying at baseline gave broadly similar results (Additional file 2: Table S2), although the differences were more marked in the social housing group where one third of the group were not working or 


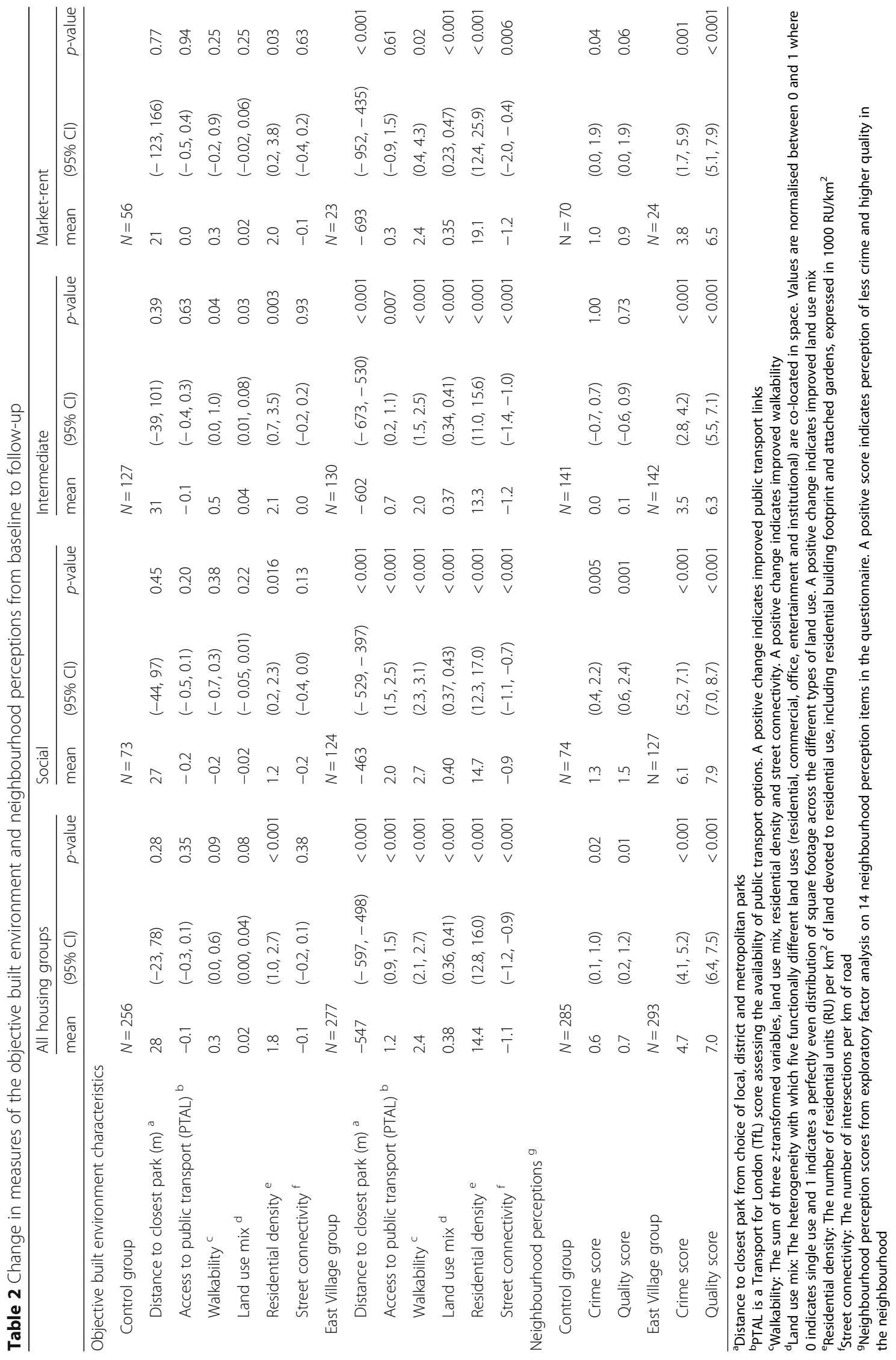




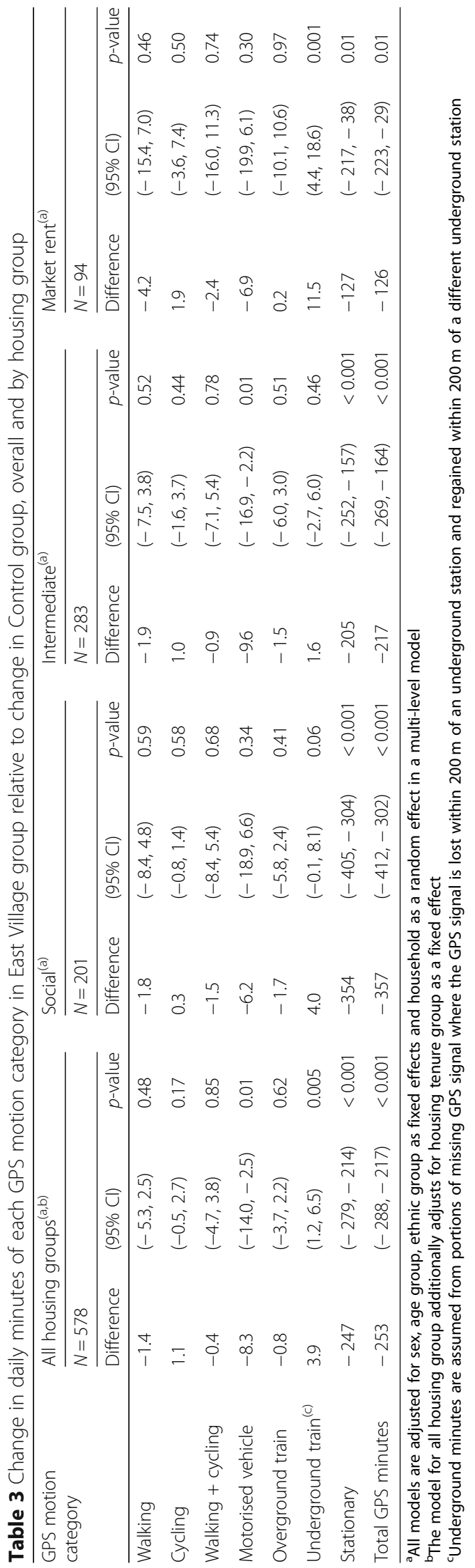


studying at baseline. Analysis of weekdays and weekend days (Additional file 3: Table S3) showed similar patterns to the "all days" analyses, although the decrease in vehicle minutes was greater at the weekend. Imputation analyses for those with GPS data at baseline but who did not provide GPS data at follow-up $(n=131)$ gave similar effect size estimates to the complete case analyses (data not shown).

\section{Discussion}

Using a novel automated approach of identifying mode of travel from combined accelerometry and GPS data, we found at two-year follow-up there was no change in the time spent walking or cycling among those who moved to East Village compared with those living elsewhere. However, the results suggested that vehicle travel had decreased, particularly in the intermediate housing group, and that underground train travel had increased, more so in the market-rent group. While use of underground train also appeared to increase among the social housing group, there appears to be little change in time spent walking.

Our finding of increased public transport underground train use and decreased vehicle use associated with the East Village development fits with a small number of other longitudinal studies carried out in the UK, which have used natural experiment study designs to examine change in travel mode and physical activity levels associated with improved travel infrastructure. Such studies have shown that town-level infrastructure initiatives to encourage active travel, in particular cycling, resulted in modest increases in self-reported cycling prevalence (with an increase from 6 to $7 \%$ over a decade) and decreased car travel [40]. Also that living closer to transport infrastructure that created new and enhanced existing walking and cycling routes across the UK, increased self-reported active travel and total physical activity after 2 years compared with those living further away [41]. However, in this study, it is noteworthy that there was no evidence of effect after 1 year and that living closer to the infrastructure was the main determinant of use at 2 years [41], more so than any other theorised cognitive mechanisms of effect [42]. Another UK example of a natural experiment which has shown that change in travel infrastructure can alter travel behaviour, includes the installation of the Cambridge Guided Busway with a traffic free cycleway and walkway, which resulted in greater self-reported weekly cycle and active commuting times [17]. Conversely, changes in parking policy to encourage car use in the work place (with free parking and fewer restrictions) resulted in increased motor vehicle trips and reduced walking and cycling [43]. This is in contrast to our study where car parking restrictions among those living in East Village led to a decrease in car travel, when compared with a control group without such restrictions. However, whilst our findings are commensurate with these other findings, differences in study methods, particularly in characterising modes of travel, do not allow for direct comparisons. Self-reported methods usually report prevalence and the type of trips taken, whereas our objective measures allow the amount of time spent in different travel modes to be quantified. Moreover, although we showed increased use of underground trains and decreased vehicle use associated with moving to East Village, there was no evidence of an effect on levels of walking, cycling or overall measures of physical activity [39]. This raises the possibility of compensatory effects where close proximity to public transport encourages use, but in turn decreases the amount of activity needed to access it. Similar compensatory effects could occur among those moving to East Village, where better walkability/closer proximity to facilities (such as parks, shops, etc.) encourage active mode of travel, but reduce the time spent travelling to reach them. Further analyses of qualitative data from this study could be used to explore these possibilities. Moreover, there is more research required on thresholds of proximity that maximise the health benefits that can be achieved through city planning and urban design.

The ENABLE London study has a number of strengths and limitations worthy of further consideration. A major strength was the clear evidence of positive change in objective measures of the built environment and travel infrastructure associated with moving to East Village, particularly in comparison with the control group who did not move or moved elsewhere and showed little or no change. In particular, the sizeable improvements in access to public transport associated with moving to East Village highlights the legacy of the Olympic Delivery Authority's transport plan for the London 2012 Olympic and Paralympic Games [44], in addition to marked increases in walkability and closer proximity to a local park (by $1 / 2 \mathrm{~km}$ or more), as well as sizeable improvements in neighbourhood perceptions of safety and quality. The robust longitudinal study design, targeted those who were seeking to move, minimising potential biases that may have occurred by including those who were not seeking to move who may have had potentially different health behaviours [39]. A unique strength of the ENABLE London study is the social diversity of participants, with representation from three housing groups (social, intermediate and market-rent housing), which allowed social gradients in effects on travel mode associated with moving to East Village to be gauged. To date there has been a dearth of studies that have directly examined or reported on social disparities in interventions to promote active travel, particularly those that have examined the effects of change in travel infrastructure $[45,46]$. While power to examine effects across social sub-groups was limited, this study allays concerns over whether such interventions 
widen social inequalities, in that effects of moving to East Village were broadly similar and in the same direction across the housing groups. This was despite marked differences in travel mode and physical activity levels between housing groups at baseline [38], showing potential benefits for all. Another major strength was the use of an automated machine learning approach, combining accelerometry and GPS data, to measure travel mode allowing more data points to contribute to the analyses, increasing statistical power to establish the presence or absence of effects. The algorithm has been described previously and has major advantages over previously used manual approaches, which are prohibitively labour intensive particularly in larger studies [22].

\section{Limitations}

Misclassification and overlap between overground and underground train travel is possible, which may lead to underestimation of effects but is likely to affect East Village and controls equally. It was also not possible to reliably distinguish public transport bus travel from car travel, thus making it difficult to accurately quantify use of all forms of public transport. Another limitation was the reduced sample size of combined ActiGraph and GPS wear time, due to participants not providing GPS data or not having equivalent days of $\geq 540 \mathrm{~min}$ accelerometer wear time. Participants were asked to re-wear their accelerometers if they didn't provide 4 days adequate data, but were not asked to re-wear their GPS monitors to encourage compliance for accelerometry as the main outcome for the ENABLE London study. The GPS monitors required charging overnight, and it's possible that some participants didn't wear or activate their GPS monitors each day. GPS monitors rely on being able to transmit a signal and it is known that this can be reduced indoors, particularly in blocks of flats rather than individual houses. The loss of GPS signal was particularly noticeable at follow-up among those living in the East Village homes, a high-rise urban environment, affecting both total GPS minutes and GPS minutes classified as stationary. Manual inspection of the GPS data indicated that the GPS signal was lost within close proximity of East Village accommodation blocks, and reappeared at a similar location, suggesting entering and exiting the accommodation block. The decreased stationary time associated with a blocked signal was therefore most likely to be indoor stationary time whilst the participants were in their homes. For example, in the social housing group, the reduction in stationary and total GPS minutes was much greater in those not working or studying at baseline $(n=70 / 201)$ i.e., those participants who are more likely to be spending longer periods of time at home. However, this loss of GPS signal inside the East Village homes will not have affected the quantification of outdoor modes of travel / motion categories (i.e., outdoor stationary time). It was not possible to test this prior to the study as East Village was not built, but future studies may wish to check GPS signal in potential indoor intervention areas to avoid such difficulties. It should be noted that loss of signal associated with underground travel did not affect the recording of activities, as proximity (within $200 \mathrm{~m}$ ) to known locations of stations allowed for these activities to be included, despite the loss of signal.

While there was no clear evidence of an effect of moving to East Village on overall physical activity levels, there are other potential health and environmental implications of increased public transport use and decreased car use worthy of consideration, particularly where small shifts in travel mode across a whole population are observed. The extent to which this was due to urban design, or policies to restrict motor vehicle ownership is unclear. Moreover, it is plausible that walkable neighbourhoods with very close proximity to public transport and amenities, decreases active transport, and more research is required to understand how to optimise urban design standards for proximity. Strategies to increase active travel could impact on air quality leading to more environmentally sustainable communities [47, 48]. However, these gains need to be offset against increased use of public transport, particularly use of London underground, where individual exposure to air pollution is high (particularly to small particulate matter, $\mathrm{PM}_{2.5}$ ) with potentially adverse health consequences [49]. This is of particular relevance to this population who are much more likely to use public transport (given London's extensive transport network system) compared with National Travel Survey data where only $8 \%$ use public transport nationally (of which half use the bus) [11]. Increased individual exposure to underground air pollution needs to be weighed against greater environmental sustainability at a population level, in order to fully appreciate the ramifications of future travel infrastructure and policy initiatives. However, this study provides an important addition to the literature providing longitudinal evidence that major investment in travel infrastructure, combined with motor vehicle parking policies, can offer a community-wide strategy to shift transport behaviours towards more sustainable ones.

\section{Supplementary information}

Supplementary information accompanies this paper at https://doi.org/10. 1186/s12966-020-0916-0.

Additional file 1: Table S1. Summary data for minutes spent in different GPS motion categories, by East Village/Control group and housing group.

Additional file 2: Table S2. Change in daily minutes of activity measured by GPS in East Village group relative to change in Control group, for those who were working or studying at baseline. 
Additional file 3: Table S3. Change in daily minutes of activity measured by GPS in East Village group relative to change in Control group, for weekdays and weekend days.

\section{Abbreviations}

ENABLE London: Examining Neighbourhood Activities in Built Living Environments in London; GIS: Geographic Information System; GPS: Global Positioning System; NHS: National Health Service (UK); NS-SEC: National Statistics Social-Economic Classification (UK); OS: Ordnance Survey (UK); PTAL: Public Transport Accessiblity Level score (Transport for London, UK)

\section{Acknowledgements}

The authors thank the East Thames Group, Triathlon Homes and Get Living London who assisted in recruiting participants into the ENABLE London study. The ENABLE London study was advised by a Steering Committee chaired by Professor Hazel Inskip (University of Southampton), with Dr. David Ogilvie (University of Cambridge) and Professor Andy Jones (University of East Anglia) as academic advisors and Mrs. Kate Worley (formerly East Thames Group Assistant Director for Strategic Housing) as the lay/ stakeholder member. The authors are grateful to the members of the ENABLE London study team (in particular Aine Hogan, Katrin Peuker, Cathy McKay) and to participating households, without whom this study would not be possible.

\section{Authors' contributions}

CGO, ARR, AE, ARC, DL, SC, BG-C, PHW and DGC designed the study and raised funding. BR, ARR, CC, DP and CGO collected data for the study; BR, ARR and CGO enrolled participants. ESL, DP, CMN, BR, ARR, CC, and CGO undertook data management. ESL analysed the data; ESL and CGO wrote the first draft of the report. ESL, DP, ARC, ASP, CMN, BR, AS, CC, DL, SC, AE, BG-C, PHW, ARR, DGC and CGO critically appraised the manuscript and approved the final draft. CGO is responsible for data integrity.

\section{Funding}

This research is being supported by project grants from the National Prevention Research Initiative (MR/J000345/1) and National Institute for Health Research (12/211/69). Diabetes and obesity prevention research at St George's, University of London is supported by the National Institute for Health Research (NIHR) Collaboration for Leadership in Applied Health Research and Care (CLAHRC) South London. CMN is supported by the Wellcome Trust Institutional Strategic Support Fund [204809/Z/16/Z]. BR was supported by a St George's, University of London, PhD Studentship. AE is funded by the UK Medical Research Council as part of the Neighbourhoods and Communities Programme (MC_UU_12017-10). BG-C is supported by an NHMRC Principal Research Fellowship (\#1107672). ARC and ASP are supported by NIHR Biomedical Research Centre at University Hospitals Bristol NHS Foundation Trust and the University of Bristol. The views expressed in this publication are those of the author(s) and not necessarily those of the NHS, the National Institute for Health Research or the Department of Health and Social Care.

\section{Availability of data and materials}

Further details of the ENABLE London study are available from the study website (http://www.enable.sgul.ac.uk/). We welcome proposals for collaborative projects. For general data sharing inquiries, contact Professor Owen (cowen@sgul.ac.uk).

\section{Ethics approval and consent to participate}

Full ethical approval was obtained from the relevant Multi-Centre Research Ethics Committee (City Road and Hampstead REC Reference 12/LO/1031). All participants provided written informed consent.

\section{Consent for publication}

Not applicable.

\section{Competing interests}

The authors declare that they have no competing interests.

\section{Author details}

${ }^{1}$ Population Health Research Institute, St George's, University of London, London, UK. ${ }^{2}$ Centre for Exercise, Nutrition and Health Sciences, University of Bristol, Bristol, UK. ${ }^{3}$ National Institute for Health Research Bristol Biomedical Research Centre, University Hospitals Bristol NHS Foundation Trust and University of Bristol, Bristol, UK. ${ }^{4}$ Department of Public Health, Environments and Society, London School of Hygiene and Tropical Medicine, London, UK. ${ }^{5} \mathrm{MRC} / \mathrm{CSO}$ Social and Public Health Sciences Unit, University of Glasgow, Glasgow, UK. ${ }^{6} \mathrm{NHMRC}$ Centre of Research Excellence in Healthy Liveable Communities, RMIT University, Melbourne, Australia.

Received: 24 July 2019 Accepted: 20 January 2020 Published online: 10 February 2020

\section{References}

1. Piercy $\mathrm{KL}$, Troiano RP, Ballard RM, et al. The physical activity guidelines for Americans. JAMA. 2018;320(19):2020-8.

2. Scarborough $P$, Bhatnagar $P$, Wickramasinghe KK, et al. The economic burden of ill health due to diet, physical inactivity, smoking, alcohol and obesity in the UK: an update to 2006-07 NHS costs. J Public Health (Oxf). 2011;33(4):527-35.

3. Department of Health. Start active, stay active: a report on physical activity from the four home countries' Chief Medical Officers: Department of Health, Physical Activity, Health Improvement and Protection Crown; 2011. https:// www.gov.uk/government/uploads/system/uploads/attachment_data/ file/216370/dh_128210.pdf.

4. World Health Organization. Global recommendations on physical activity for health. Available from http://www.who.int/dietphysicalactivity/publications/ 9789241599979/en/ [Accessed July 2018] 2010.

5. NHS Digital. Statistics on Obesity, Physical Activity and Diet. England; 2017. Available from https://www.gov.uk/government/statistics/statistics-onobesity-physical-activity-and-diet-england-2017 [Accessed July 2018]

6. Eijsvogels TM, Molossi S, Lee DC, et al. Exercise at the extremes: the amount of exercise to reduce cardiovascular events. J Am Coll Cardiol. 2016;67(3): 316-29.

7. Kyu HH, Bachman VF, Alexander LT, et al. Physical activity and risk of breast cancer, colon cancer, diabetes, ischemic heart disease, and ischemic stroke events: systematic review and dose-response meta-analysis for the global burden of disease study 2013. BMJ. 2016;354:i3857.

8. Baker PR, Francis DP, Soares J, et al. Community wide interventions for increasing physical activity. Cochrane Database Syst Rev. 2015;1:CD008366.

9. Chandrabose M, Rachele JN, Gunn L, et al. Built environment and cardiometabolic health: systematic review and meta-analysis of longitudinal studies. Obes Rev. 2019;20(1):41-54.

10. Watts $N$, Adger WN, Agnolucci $P$, et al. Health and climate change: policy responses to protect public health. Lancet. 2015;386(10006):1861-914.

11. Patterson $R$, Webb E, Millett $C$, et al. Physical activity accrued as part of public transport use in England. J Public Health (Oxf). 2018;41:222-30.

12. Kamruzzaman $M$, Washington $S$, Baker $D$, et al. Does residential dissonance affect residential mobility? Transport Res Rec. 2013;2344:59-67.

13. Smith M, Hosking J, Woodward A, et al. Systematic literature review of built environment effects on physical activity and active transport - an update and new findings on health equity. Int J Behav Nutr Phys Act. 2017;14(1):158

14. Saunders LE, Green JM, Petticrew MP, et al. What Are the Health Benefits of Active Travel? A Systematic Review of Trials and Cohort Studies. PLoS One. 2013;8(8):e69912.

15. Audrey S, Procter S, Cooper AR. The contribution of walking to work to adult physical activity levels: a cross sectional study. Int J Behav Nutr Phys Act. 2014;11(1):37.

16. Sahlqvist S, Song Y, Ogilvie D. Is active travel associated with greater physical activity? The contribution of commuting and non-commuting active travel to total physical activity in adults. Prev Med. 2012;55(3):206-11.

17. Panter J, Heinen $E$, Mackett $R$, et al. Impact of new transport infrastructure on walking, cycling, and physical activity. Am J Prev Med. 2016;50(2):e45-53.

18. Stopher P, FitzGerald C, Xu M. Assessing the accuracy of the Sydney household travel survey with GPS. Transportation. 2007:34(6):723-41.

19. Adams SA, Matthews CE, Ebbeling CB, et al. The effect of social desirability and social approval on self-reports of physical activity. Am J Epidemiol. 2005;161(4):389-98. 
20. Brondeel R, Pannier B, Chaix B. Using GPS, GIS, and accelerometer data to predict transportation modes. Med Sci Sport Exer. 2015;47(12):2669-75.

21. Ellis $K$, Godbole $S$, Marshall $S$, et al. Identifying active travel behaviors in challenging environments using GPS, accelerometers, and machine learning algorithms. Front Public Health. 2014;2:36.

22. Procter DS, Page AS, Cooper AR, et al. An open-source tool to identify active travel from hip-worn accelerometer, GPS and GIS data. Int J Behav Nutr Phys Act. 2018;15(1):91.

23. Gebel $K$, Ding D, Foster $C$, et al. Improving current practice in reviews of the built environment and physical activity. Sports Med. 2015;45(3):297-302.

24. Bauman A. The physical environment and physical activity: moving from ecological associations to intervention evidence. J Epidemiol Community Health. 2005;59(7):535-6.

25. Craig P, Cooper C, Gunnell D, et al. Using natural experiments to evaluate population health interventions: new Medical Research Council guidance. J Epidemiol Community Health. 2012;66(12):1182-6.

26. Humphreys DK, Panter J, Sahlqvist S, et al. Changing the environment to improve population health: a framework for considering exposure in natural experimental studies. J Epidemiol Community Health. 2016;70(9):941-6.

27. Ding D, Nguyen B, Learnihan V, et al. Moving to an active lifestyle? A systematic review of the effects of residential relocation on walking, physical activity and travel behaviour. Br J Sports Med. 2018;52(12):789-99.

28. Ram B, Nightingale CM, Hudda MT, et al. Cohort profile: examining Neighbourhood activities in built living environments in London: the ENABLE London-Olympic Park cohort. BMJ Open. 2016;6(10):e012643.

29. Freedson PS, Melanson E, Sirard J. Calibration of the computer science and applications, Inc accelerometer. Med Sci Sports Exerc. 1998;30(5):777-81.

30. Kelly LA, McMillan DG, Anderson A, et al. Validity of actigraphs uniaxial and triaxial accelerometers for assessment of physical activity in adults in laboratory conditions. BMC Med Phys. 2013;13(1):5.

31. Transport for London. Accessibility and connectivity. Available from https:// tfl.gov.uk/info-for/urban-planning-and-construction/transport-assessmentguide/transport-assessment-inputs/accessibility-analysis [Accessed November 2018] 2018.

32. Ordnance Survey (GB). Meridian 2, v.12: EDINA Digimap Ordnance Survey Service, 2016

33. GiGL. Greenspace Information for Greater London CIC. Available from https://www.gigl.org.uk/ [Accessed September 2019].

34. Mayor of London. The London Plan: the spatial development strategy for London consolidated with alterations since 2011. Available from https:// www.london.gov.uk/sites/default/files/the_london_plan_2016_jan_2017_fix. pdf [Accessed November 2019] 2016.

35. Office for National Statistics. The National Statistics Socio-economic Classification User Manual. Basingstoke: Palgrave Macmillan; 2005.

36. International Labour Organization (ILO). Resolutions Concerning Economically Active Population, Employment, Unemployment and Underemployment Adopted by the 13th International Conference of Labour Statisticians: OECD [Available at: https://stats.oecd.org/glossary/detail. asp?ID=2791]; 1982

37. Ram B, Shankar A, Nightingale CM, et al. Comparisons of depression, anxiety, well-being, and perceptions of the built environment amongst adults seeking social, intermediate and market-rent accommodation in the former London Olympic Athletes' village. Health Place. 2017;48:31-9.

38. Nightingale CM, Rudnicka AR, Ram B, et al. Housing, neighbourhood and sociodemographic associations with adult levels of physical activity and adiposity: baseline findings from the ENABLE London study. BMJ Open. 2018:8(8):e021257.

39. Nightingale CM, Limb ES, Ram B, et al. The effect of moving to East Village, the former London 2012 Olympic and Paralympic games Athletes' village, on physical activity and adiposity (ENABLE London): a cohort study. Lancet Public Health. 2019:4(8):e421-e30.

40. Goodman A, Panter J, Sharp SJ, et al. Effectiveness and equity impacts of town-wide cycling initiatives in England: a longitudinal, controlled natural experimental study. Soc Sci Med. 2013;97:228-37.

41. Goodman A, Sahlqvist S, Ogilvie D. New walking and cycling routes and increased physical activity: one- and 2-year findings from the UK iConnect study. Am J Public Health. 2014;104(9):e38-46.

42. Panter J, Ogilvie D, iConnect c. Theorising and testing environmental pathways to behaviour change: natural experimental study of the perception and use of new infrastructure to promote walking and cycling in local communities. BMJ Open. 2015;5(9):e007593.
43. Knott CS, Sharp SJ, Mytton OT, et al. Changes in workplace car parking and commute mode: a natural experimental study. J Epidemiol Community Health. 2019;73(1):42-9.

44. Mayor of London. Inspired by 2012: the legacy from the Olympic and Paralympic Games - Fourth annual report - summer 2016. Available from https://www.gov.uk/government/publications/olympic-and-paralympiclegacy-inspired-by-2012-fourth-annual-report [Accessed August 2018] 2016.

45. Ogilvie D, Egan M, Hamilton V, et al. Promoting walking and cycling as an alternative to using cars: systematic review. BMJ. 2004;329(7469):763.

46. Bambra C, Gibson M, Sowden A, et al. Tackling the wider social determinants of health and health inequalities: evidence from systematic reviews. J Epidemiol Community Health. 2010;64(4):284-91.

47. Giles-Corti B, Foster S, Shilton T, et al. The co-benefits for health of investing in active transportation. N S W Public Health Bull. 2010;21(5-6):122-7.

48. Hunter RF, Boeri M, Tully MA, et al. Addressing inequalities in physical activity participation: implications for public health policy and practice. Prev Med. 2015;72:64-9.

49. (COMEAP) CotMEoAP. Statement on the evidence for health effects in the travelling public associated with exposure to particulate matter in the London Underground. 2018. (Accessed April 2019).

\section{Publisher's Note}

Springer Nature remains neutral with regard to jurisdictional claims in published maps and institutional affiliations.
Ready to submit your research? Choose BMC and benefit from:

- fast, convenient online submission

- thorough peer review by experienced researchers in your field

- rapid publication on acceptance

- support for research data, including large and complex data types

- gold Open Access which fosters wider collaboration and increased citations

- maximum visibility for your research: over $100 \mathrm{M}$ website views per year

At BMC, research is always in progress.

Learn more biomedcentral.com/submissions 